Rev Soc Esp Dolor

2015; 22(4): 180

\section{Evaluación de la intensidad de dolor mediante la escala numérica en pacientes con metástasis óseas antes y después del tratamiento con radioterapia}

\section{Sr. Director:}

Con el objetivo de determinar la intensidad del dolor mediante escala numérica en pacientes con metástasis óseas antes, durante y después del tratamiento con radioterapia, hemos realizado un estudio prospectivo, observacional, unidimensional, el cual se realizó en el Centro Médico Nacional "20 de Noviembre" ISSSTE, en el periodo comprendido de septiembre a diciembre de 2014, donde se incluyeron todos los pacientes que aceptaron participar en este estudio: estos fueron 30 pacientes que cumplieron con los criterios de inclusión y que fueron instruidos para valorar su dolor por medio de una escala numérica.

Se realizó una valoración del dolor previa a iniciar tratamiento y su evolución a los 14 y 30 días. Los datos fueron analizados por medio del programa SPSS versión 22. Se dieron a conocer los resultados en forma de medias, medianas y desviaciones estándar. Se llevó a cabo estadística descriptiva y el análisis bivariado se hizo con t de Student y análisis comparativo con Pearson.

La principal etiología fue cáncer de mama con un total de 16 casos que representa 53,3\% de los casos analizados en mujeres, mientras que en el grupo masculino el que tuvo mayor incidencia fue el cáncer de próstata con 4 casos $(13,3 \%)$; en tercer lugar se obtuvo melanoma que identificó 3 casos $(10 \%)$. El análisis demográfico de la población demostró una prevalencia del $76 \%$ en pacientes femeninos y $24 \%$ masculinos. La media de edad es de 58 años. La dosis promedio inicial de radioterapia fue de 30 gys, dosis media de 23 gys. La mayoría de los pacientes antes del tratamiento valoraban su dolor de acuerdo a la escala numérica con media de 8,6/10. A los 14 días de tratamiento la media fue de 4,9/10. A los 30 días la media fue de 3,5/10. En cuanto a la escala numérica fue disminuyendo con los días de intervención de radioterapia: a los 14 días $(\mathrm{p}=0,4)$ y a los 30 días $(\mathrm{p}=0,12)$. Se obtuvieron $\mathrm{t}$ de Student con un valor de $\mathrm{t}=9,6$ para la intervención a 14 días y $\mathrm{t}=12,9$ para 30 días.

La escala numérica del dolor se mostró efectiva en la evaluación del dolor en cualquier tiempo de la intervención terapéutica lo que traduce su efectividad para dar un acercamiento a la realidad de la sintomatología del paciente

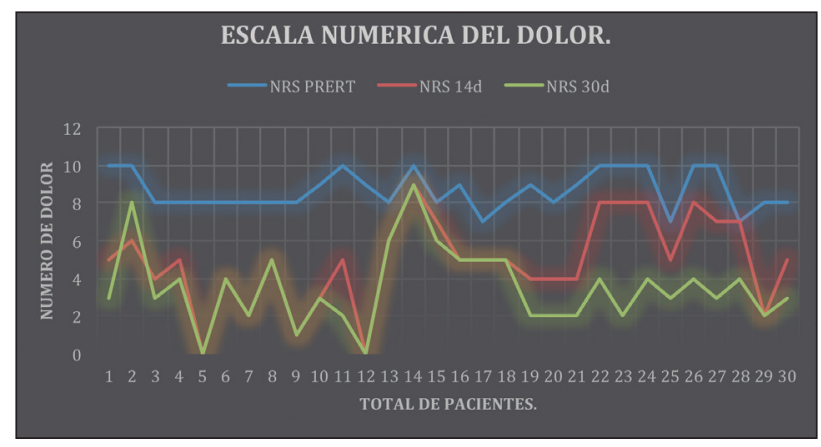

Fig. 1. Histograma de frecuencias de comportamiento de la escala numérica del dolor de acuerdo al tratamiento.

por lo que su uso, incluso en metástasis óseas, está completamente aceptado (Fig. 1).

\section{F. J. Ardisson Zamora ${ }^{1}$, R. C. Báez Fernández ${ }^{2}$ y F. Guardado Bermúdez ${ }^{3}$}

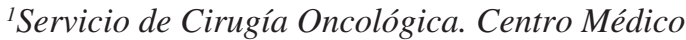
Nacional "20 de noviembre”. ISSSTE. México, DF. ${ }^{2}$ Algología. Práctica Privada. Santiago de los Caballeros, Republica Dominicana. ${ }^{3}$ Servicio de Cirugía General. Hospital Regional de Ciudad Madero. Tampico, Tamaulipas. México

\section{BIBLIOGRAFÍA RECOMENDADA}

1. Andrade RS, Proctor JW, Slack R, et al. A simple and effective daily pain management method for patients receiving radiation therapy for painful bone metastases. Int J Radiat Oncol Biol Phys 2010;1;78(3):855-9.

2. Smith H S, Mohsin I. Painful boney metastases. Korean J Pain 2013;26(3):223-41.

3. Everts V, Dalaisse JM, Korper W, et al. The bone lining cell: Its role in cleaning Howship lacunae and initiation bone formation. J Bone Miner Res 2002;17:77-90.

4. Mercadante S. Malignant bone pain: Pathophysiology and treatment. Pain 1997;69:1-18.

5. Konski A, James J, Hartsell W, et al. Economic analysis of radiation therapy oncology group (RTOG) 97-14: Multiple versus single fraction radiation treatment of patients with bone metastases. Am J Clin Oncol 2009;32:423-8. 